\title{
La escena de la traducción poética. La voz de Kathleen Raine en español
}

\section{(The scene of poetic translation. The Voice of Kathleen Raine in Spanish)}

\author{
MARÍA LAURA SPOTURNO \\ Universidad Nacional de La Plata/ \\ Consejo Nacional de Investigaciones Científicas y Técnicas
}

\begin{abstract}
Fecha de recepción: 19 de septiembre de 2013
Fecha de aceptación: 30 de septiembre de 2013

Resumen: Este artículo, que se inscribe en el ámbito de la traducción poética, tiene dos objetivos principales; por un lado, se propone señalar algunas particularidades que atañen a la traducción de poesía y, por el otro, ofrecer una aproximación a la traducción al español de la obra poética de la poeta y crítica británica Kathleen Raine (1908-2003). Más específicamente, se examinará la edición bilingüe En una desierta orilla, cuya traducción, prólogo y notas han sido responsabilidad de Rafael Martínez Nadal (1981) con el propósito de elucidar las estrategias y agenda de trabajo que orientaron la tarea de este reconocido escritor, crítico y traductor español.
\end{abstract}

Palabras clave: Traducción poética, Kathleen Raine, Rafael Martínez Nadal.

Abstract: This article, which falls within the scope of poetry translation, has two main goals. First, it points out some of the characteristics of poetry translation, and second, it offers a first approach to the Spanish translation of the poetic work of British critic and poet Kathleen Raine (1908-2003). More specifically, the article explores the bilingual edition En una desierta orilla, whose translation, preface and notes have been authored by Rafael Martínez Nadal (1981) in order to elucidate the translation strategies and the translator's agenda guiding the task of this well-known Spanish writer, critic and translator.

Key words: Poetic translation, Kathleen Raine, Rafael Martínez Nadal. 


\section{INTRODUCCIÓN \\ En este trabajo, nos proponemos realizar una aproximación a la} traducción de la obra poética de Kathleen Raine (1908-2003) al español; más específicamente, al estudio del poemario On a Deserted Shore de la poeta inglesa (1973), que fue editado en España como un volumen bilingüe de poesía titulado En una desierta orilla, y cuya traducción, prólogo y notas fueron de Rafael Martínez Nadal (1981). La consideración de este interesante caso de traducción nos obliga a revisar algunas nociones sobre la traducción poética, ámbito, en el que, tal como afirma Masseau (2007), confluyen el arte poético y la reflexión teórica sobre la posibilidad misma de la traducción de poesía, sus mecanismos y particularidades específicas.

Es conocida la afirmación de Jakobson ([1959] 1981) respecto de la intraducibilidad de la poesía y de la necesidad de elaborar estrategias que, a su juicio, deben situarse en el campo de la transposición creativa, más que en el de la traducción. La perspectiva de Jakobson se fundamenta, pues, en la consideración de la carga semántica que se atribuye a cada nivel de la lengua y a los recursos como la rima, la métrica, los juegos de palabras, entre otros, en el dominio del poema. Ahora bien, aun si la posibilidad de traducir poesía sigue siendo tema de debate en distintos círculos, prevalece el hecho incontestable, como apunta Mounin (1963) para el caso de la traducción en general, de que la traducción poética existe de facto y de que constituye, por otra parte, una manifestación artística clave para el diálogo y comunicación entre distintas sociedades y culturas. En este sentido, la traducción de Martínez Nadal, que reconoce la dificultad inherente a la tarea de la traducción poética pero que no por ello admite su imposibilidad, plantea una recreación del texto fuente que puede describirse como autónoma. En efecto, a través de una serie de estrategias discursivas y literarias, el traductor reelabora el texto de Raine a fin de forjar una relación estrecha con el ámbito sociocultural en el que circulará la obra traducida. Ciertamente, esta reelaboración, que atañe tanto el plano de las intertextualidades como el del registro y el estilo, supone y construye la figura de un lector determinado. Asimismo y en relación con la afirmación de Jakobson respecto de los recursos formales de la poesía, el traductor no se propone, por considerarlo una empresa prácticamente imposible, la reproducción de las rimas y ritmos del original inglés, sino más bien la recreación de su sentido poético y musicalidad a partir de los recursos que ofrecen el español y su tradición poética.

Es posible que la supuesta intraducibilidad de la poesía se origine en el hecho de que el género lírico, como indica Bassnett (1998), ha sido largamente caracterizado por críticos, poetas y traductores como un género 
impenetrable. Se trata de un velo de exclusividad que rodea a la palabra poética y a quienes la practican, en general, y no tan solo a quienes se proponen la tarea de su traducción. La noción de que el poeta procede por inspiración divina o de otro tipo es de vieja tradición y, como señala Robinson (2001), contribuye a relegar la figura del traductor a un espacio de subordinación. Al discutir la instancia del sujeto de la traducción y las subjetividades del traductor, Robinson afirma que la actividad del escritor y la del traductor se organizan a partir de los mismos procedimientos y estrategias, razón por la que el estatus del traductor no debería entenderse como desigual o inferior al del escritor. En este mismo sentido, al preguntarse por la pérdida específica que supone la traducción de poesía, Lefevere ([1992] 1997) ofrece una respuesta contundente en tanto coloca en un pie de igualdad la escritura del mentado texto original y la de la traducción. En uno y otro tipo de escritura, se pierde, como apunta el autor, la posibilidad de obtener una "combinación ideal" de estrategias y persiste así la sensación, para el poeta y también para el traductor, de que el texto "podría haber sido mejor", siempre mejor. Efectivamente, Martínez Nadal pergeña y lleva adelante su tarea desde una perspectiva teóricometodológica que considera, como ya se ha mencionado, la labor del traductor como autónoma. Más aún, la traducción de Martínez Nadal revela un fino equilibrio de procedimientos y estrategias que ponen en evidencia no solo una gran autonomía por parte del traductor, sino también un respeto sostenido por el texto original, que se funda en un conocimiento profundo de la obra, en la consulta permanente con la poeta y en la puesta en escena de una agenda de trabajo bien definida ${ }^{1}$. El posicionamiento del traductor resulta evidente tanto en el espacio paratextual de la obra que ofrece el traductor como en el cuerpo de la obra traducida.

Dado que cada poema le propone al traductor un desafío nuevo y que, potencialmente hablando, pueden existir tantas versiones de un poema como traductores que decidan acometer la tarea de su traducción, es menester para el traductor establecer los parámetros y normas que guían una traducción poética en particular. Sin lugar a dudas y como postula Venuti (2013), la traducción de poesía excede en mucho la recreación de un propósito o efecto que podríamos llamar comunicativo. Tal como destaca este autor, la traducción de poesía desafía claramente la noción de que

${ }^{1}$ Como se podrá constatar, la traducción de la obra de Raine revela el mismo respeto y meticulosidad que la celebrada edición de los trabajos póstumos de Federico García Lorca que Martínez Nadal publicó en 1980. 
existe una invariante funcional o semántica que deba o pueda trasladarse de una lengua a otra, y prueba de ello es, justamente, la multiplicidad de versiones o traducciones diferentes, pero aceptables en relación con un contexto sociocultural determinado, que pueden existir de un mismo poema u obra poética ${ }^{2}$. Así, Bassnett (1998), que aborda el fenómeno de la traducción de poesía a partir de una mirada cultural amplia, intenta elucidar no solo las exigencias formales que impone la traducción de un poema particular sino las condiciones y particularidades que caracterizan su lectura y recepción en la cultura de origen y en la lengua y cultura en la que circulará la obra traducida. El caso que nos ocupa reviste, como veremos, un interés especial, pues Martínez Nadal encauza su lectura y versión del poemario de Raine en pos de que su traducción pueda ser bien recibida en el seno de la lengua receptora y de la comunidad de lectores a quienes la obra traducida está dirigida en primera instancia.

En lo que sigue, examinaremos el poemario bilingüe En una desierta orilla teniendo en cuenta las líneas de análisis esbozadas en esta Introducción. En suma, este artículo intentará mostrar que la traducción de Martínez Nadal ofrece una recreación del texto original que se sustenta en una visión de la traducción como tarea autónoma y no subsidiaria. En este sentido, se comprobará que la tarea del traductor desafía las nociones de la impenetrabilidad e intraducibilidad de la poesía. Más aún, en el universo de la obra, el traductor ejerce su propia voz, la cual se materializa tanto en el espacio del texto traducido como en el paratexto del traductor. La voz del traductor, que se construye en relación con pautas de trabajo autodeterminadas, recrea el texto original en función de la lengua y cultura receptoras y, en especial, de los lectores vinculados a la editorial Hiperión. Según lo expresado hasta ahora, el trabajo se organiza del siguiente modo. En la sección 2, presentaremos algunos datos relevantes acerca de la vida personal y profesional de la poeta Kathleen Raine y pasaremos revista por las características principales del poemario On a Deserted Shore. En la sección 3, ofreceremos el estudio de algunos aspectos centrales de la obra para, finalmente, en la sección 4 , exponer las conclusiones que se derivan del análisis realizado.

\section{KatHleEn RaINe y ON A DESERTED SHORE}

Kathleen Jessie Raine nació en Ilford, Essex en 1908 en el seno de una familia constituida por una madre escocesa, de la que heredó su amor

\footnotetext{
${ }^{2}$ Por ejemplo, Lefevere ([1992] 1997) señala la viabilidad de distintas versiones que se han realizado de la poesía del poeta latino Catulo y Bassnett (1998) llama la atención sobre un conjunto de traducciones al inglés de La divina comedia de Dante.
} 
por las letras, la música y el paisaje, y de un padre inglés, de quien aprendió la disciplina y el rigor en el trabajo. Contrajo matrimonio dos veces y tuvo dos hijos con su segundo esposo. Ninguna de estas uniones resultó perdurable ni trascendente para la poeta y crítica inglesa, quien conoció el amor verdadero en el encuentro con el naturalista y autor escocés Gavin Maxwell (1914-1969). Se formó en el área de las ciencias naturales en el Girton College de la Universidad de Cambridge, institución en la que ingresó tras haber obtenido una prestigiosa beca. Según Raine, la literatura no debía ser objeto de estudio en la universidad, sino parte de la vida de cualquier persona culta. El talento de Raine como poeta, al igual que su pensamiento agudo como teórica, ha sido objeto de la crítica y de noticia en diarios británicos y estadounidenses como The Times, The Guardian y The New York Times. Tanto su poesía como sus investigaciones en torno a las figuras de Blake y Yeats, merecedoras de distinciones y premios, han transcendido las fronteras geográficas e idiomáticas. Su relación de amistad con Carlos de Inglaterra se tradujo en un gran apoyo por parte del príncipe a su obra y a la fundación en 1990 de la Academia Temenos, una organización dedicada, desde sus inicios, a la enseñanza y difusión del arte y la imaginación y a la recuperación de una conciencia de la espiritualidad, en la que Raine tuvo una participación destacada. Falleció en Londres en 2003 a la edad de noventa y cinco años.

El bello poemario On a Deserted Shore fue publicado en Reino Unido por Dolmen Press/ Hamish Hamilton en 1973. Ciertamente, para Raine ([c.1990] 2004), la poesía y el arte, en general, se presentan como una necesidad vital, ineludible; el arte tiene, pues, el poder de educar y sanar. Tal como advierte Keebley (2008), en esta obra, Raine explora con maestría inigualable el paso del espíritu por la tierra a través de una serie de poemas que dejan una gran impronta en el lector. Con un estilo lacónico, de traza limpia y escueta, aunque no por ello simple, en On a Deserted Shore Raine presenta un poemario constituido por ciento treinta poemas muy breves. El título del poemario alude a la geografía propia del noroeste de Escocia y, más específicamente, a la playa de Sandaig, lugar en el que Maxwell tenía una finca. La apertura y el cierre de la obra son dos poemas más extensos, que dan cohesión interna al texto, al igual que el epígrafe de probable reminiscencia agustiniana que colabora a instaurar el tono y el tema que caracterizan a la obra en su conjunto: Anima est ubi amat, non ubi animat (El alma está donde se ama, no donde se vive). Se trata, en efecto, de poemas que comparten algunos de los preceptos del minimalismo y que organizan su estructura despojada a partir de tan solo cuatro u ocho versos. 
Los dos o tres últimos versos de cada poema aportan generalmente el colofón que concluye una situación, un pensamiento o un sentir. La obra transita e indaga los temas del romanticismo, como la adoración del mundo de la naturaleza, la creencia de que la imaginación es superior a la razón, la devoción por la belleza, la fe en el amor y también en el dolor, la fascinación por el pasado, la recuperación de los mitos y del misticismo, entre otros. La innovación de esta poeta reside probablemente en la adopción de una perspectiva propia, la cual le otorga singularidad y trascendencia a su obra, que canta con desesperación, además, la pérdida del ser amado, el atesoramiento de la memoria y una renovada fe en el poder del sueño que inunda algunos de los poemas. El poemario está dedicado a la historia de amor más importante de la vida de Raine, es decir, a la relación que la poeta mantuvo con Maxwell. Este amor marcó la vida de Raine para siempre, ya que en ese encuentro la poeta percibió una unión que trascendía el plano de lo terrenal y que la hermanaba definitivamente a Maxwell, a pesar de no ser correspondida por él. Los poemas exponen ante el lector, con crudeza y sin artificios, no solo el dolor profundo por la pérdida temprana del ser amado sino la consecuente e insoslayable pérdida de uno mismo, el abismo, la desazón. Concebida como un todo, la obra muestra sobre el final la luz que se entremete para cerrar el poemario, acaso en la esperanza del nuevo encuentro con el ser querido ${ }^{3}$.

\section{EL TIEMPO DE LA TRADUCCIÓN: EN UNA DESIERTA ORILLA}

La edición bilingüe En una desierta orilla apareció en 1981 en Madrid con el aval del prestigioso sello editorial de Hiperión. La traducción, realizada por el renombrado escritor, crítico y traductor Rafael Martínez Nadal (1903-2001) ${ }^{4}$, fue tratada por El País el mismo día de su lanzamiento, contando con la presencia de la poeta británica, de su traductor y del célebre poeta granadino Luis Rosales $(1910-1992)^{5}$. El artículo del diario

\footnotetext{
${ }^{3}$ Según confirma Martínez Nadal en su prólogo, en el último tomo de su autobiografía, The Lion's Mouth, Raine (1977) presenta esta parte de su vida desde una perspectiva desoladora y en un tono mucho más crudo.

${ }^{4}$ Recordemos que Rafael Martínez Nadal desarrolló una importante labor sobre la obra de distintos artistas españoles exiliados como Luis Cernuda. Su estrecha amistad con Federico García Lorca lo convierte en una figura emblemática para la escena cultural española.

${ }^{5}$ Digamos, a título informativo, que la poeta ya estaba incluida en una prestigiosa Antología de poetas ingleses modernos (Madrid: Gredos, 1963), con introducción de Dámaso Alonso, en la que dos poemas de la autora: "For posterity" y "Winter fire", fueron trasladados al español en espléndidos alejandrinos por Marià Manent.
} 
destaca las relaciones que pueden establecerse entre la autora y su poemario y autores españoles como Bécquer, García Lorca, Calderón y los místicos españoles San Juan de la Cruz y Santa Teresa. Así, el texto del artículo trata de señalar los lazos que existen entre la poeta que Madrid recibe en su casa y, más importante aún, en su lengua y una tradición de autores españoles bien establecida, que Raine conoce e incluso ha traducido, como es el caso de la obra de Calderón. Asimismo, el texto pone de relieve lo que podríamos denominar como "la mirada filosófica" de Raine y su fuerte vínculo con el neoplatonismo, problemática sobre la que también indaga su obra poética. De este modo, el artículo instituye y legitima una imagen particular de la poeta británica en el espacio local en el que ahora circularán sus poemas a través de la traducción. Se trata de una imagen que, efectivamente, aparece recreada en la traducción poética, la cual, construye su propio lector.

En toda traducción que se propone como autónoma, media, necesariamente, el establecimiento de criterios y pautas que orientan el trabajo del traductor. Cabe preguntarse, entonces, ¿cómo se posiciona el traductor frente a la tarea de verter al español la belleza, la emoción y el carácter sublime de los poemas de Raine? La exploración de las estrategias adoptadas por el prestigioso traductor nos permitirá, no solo apreciar su quehacer, sino releer los poemas infundidos por la interpretación crítica y teórica que se impone en la traducción.

\subsection{El paratexto del traductor}

Para examinar el posicionamiento del traductor nos resulta de gran ayuda indagar sobre la dimensión de la paratextualidad. Según Jones ([1998] 2009), las introducciones, notas y glosarios, entre otros elementos, se constituyen en el espacio en el que el traductor literario ejerce su propia voz y adquiere así visibilidad. En una desierta orilla no es una excepción a esta regla. En efecto, al tratarse de un traductor reconocido y respetado en la esfera de injerencia de la traducción, es frecuente que este pueda, como de hecho ocurre en el poemario aquí tratado, dejar sentada no solo su mirada sobre la obra, la autora y la traducción, sino también su nombre, que aparece en la cubierta del libro. No obstante, cabe recordar que, a la consideración de los elementos paratextuales utilizados por el traductor, habrá que sumarle la evaluación de las estrategias que se evidencian, como afirma Willson (2004), a partir de la comparación crítica del texto fuente y el texto meta. 
El poemario, presentado en una edición bilingüe, está precedido por un prólogo de diecisiete páginas que introduce algunos aspectos claves de la vida personal y profesional de Raine. Asimismo, en el prólogo Martínez Nadal comenta acerca del carácter y la generosidad de Raine, quien en 1950 le abrió las puertas de su casa de Chelsea y con quien, además, trabajó durante los años en los que, en colaboración, acometieron la tarea de traducir al inglés La vida es sueño de Calderón, traducción que se publicó en 1968. Solo dos páginas de este prólogo están destinadas a la traducción, lo cual nos permite señalar que el traductor se posiciona como crítico antes que como traductor literario. Recordando algunas nociones de Todorov (1968) acerca de la lectura del crítico, podríamos establecer un paralelismo entre la tarea del crítico y la del traductor, pues ambos escriben un texto a partir de la interpretación que realizan de un texto determinado. "¿Cómo cabe escribir un texto permaneciendo fiel a otro texto, conservándolo intacto?" (op. cit.: 26), se pregunta Todorov. Media, como indica el autor, un proceso de selección, supresión y adición que acompaña cada lectura, que no puede reproducir lo mismo que el texto al que alude, porque la nueva escritura suprime, aun si momentáneamente, el texto primero. La actividad del traductor está sujeta a algunas de estas restricciones, aun cuando el ideal del traductor sea, como manifiesta, por su parte, Martínez Nadal (1981), "reproducir con absoluta fidelidad forma, espíritu, letra y resonancias del poema original" (23), y continúa, "ideal, como todos, inasequible" (op. cit.).

En la última sección del prólogo, Martínez Nadal consigna las normas que se autoimpuso para llevar adelante su tarea. En primer lugar y como se ha anticipado, determinó no reproducir en español las rimas y ritmos que caracterizan el poema en inglés, tarea que considera lleva, en la mayoría de los casos, al fracaso de una traducción poética. En segundo término, se propuso como ideal aspirar a una versión del poema en español que resultara lo más cercana posible al sentido y a la letra del poema original. De este modo, la traducción opera generalmente palabra por palabra, verso por verso. En la medida de lo posible, la traducción intenta recuperar las citas e intertextualidades del original, aspecto que resulta particularmente evidente en la reelaboración de las alusiones bíblicas, y mantiene la puntuación, en ocasiones no académica de los poemas. Recrear la musicalidad de los poemas aparece como uno de los desafíos que el traductor enfrenta en la traducción de esta obra. La misión general de Martínez Nadal ha sido "esforzarse por entreoír la idea-ritmo generadora del poema" (óp.cit.: 24) para luego reelaborar esa idea en la traducción. Las abundantes notas que acompañan la traducción se proponen explicar las 
aparentes desviaciones que el lector puede advertir en esta edición bilingüe. A diferencia de otros traductores, Martínez Nadal no ha empleado aquí el recurso de la nota llamada con un subíndice; es decir, las notas constituyen un espacio paratextual que funciona como un anexo de la obra pero que no interrumpen el hilo de la lectura del poemario ni llevan al lector por las distintas zonas del texto, ya que las notas no están señaladas en los poemas. Es posible entrever dos cuestiones en esta decisión: por un lado, la voluntad expresa de no echar mano del recurso, en ocasiones vergonzante, de las notas del traductor, las cuales muchas veces aparecen como textos paralelos que suplen o complementan aquello que el traductor no pudo plasmar en la traducción; y, por otro lado, la edición bilingüe sin notas indexadas implica la intención clara, por parte del traductor, de someter su trabajo al juicio del lector, quien a su paso por la obra también escribirá su propia lectura de los poemas, recurriendo o no a las notas que aparecen a final de la edición. La consideración del lector de la traducción aparece únicamente esbozada en el espacio de las notas, en el que se dan cita explicaciones y referencias para su beneficio.

\subsection{Análisis de los poemas}

En cuanto al análisis de los poemas, otorgaremos especial atención a tres aspectos que se desprenden del estudio de este caso de traducción poética: la recreación de alusiones e intertextualidades bíblicas, clásicas y míticas; la apropiación del texto original a partir de las tradiciones literarias correspondientes a la cultura receptora; la reelaboración de la sintaxis, el estilo y el registro en pos de la institución de un lenguaje más poético que el que celebra el original y de un lector particular para la traducción.

En relación con las alusiones e intertextualidades, nos detendremos en lo que podríamos definir como la primera unidad poemática de la obra, que se extiende desde el primer al cuarto poema. Los primeros poemas establecen, entre otras cuestiones, algunas pautas respecto de la relación amorosa entre el yo lírico que se construye en los poemas y su amado desaparecido. La transición del epígrafe latino al poemario es armoniosa ${ }^{6}$. El primer poema retoma el sentido de la máxima del epígrafe y propone nuevas miradas: una, proveniente del evangelio de Mateo (6.21) ${ }^{7}$, acerca de

${ }^{6}$ Se recuerda el epígrafe para beneficio del lector: Anima est ubi amat, non ubi animat (El alma está donde se ama, no donde se vive).

${ }^{7}$ Allí donde esté tu tesoro, estará también tu corazón (Mateo, 6.21) / For where your treasure is, there will your heart be also (Matthew, 6.21). 
la misma cuestión elemental sobre la que gira toda la obra, el amor y la inmanencia, y la otra, una cita encubierta de Plotino (c. 204/5-270), que recoge a su vez la famosa traducción de Thomas Taylor (1895) de la obra de este filósofo de la Antigüedad. Asimismo, introduce el tema de Narciso, que luego reaparece, como veremos más adelante, en el segundo poema con la mención de Eco, que evoca el Libro III de la Metamorfosis de Ovidio (c. 1-8) y los mitos creacionales según el imaginario órfico. A continuación, transcribimos el poema 1 y su traducción:

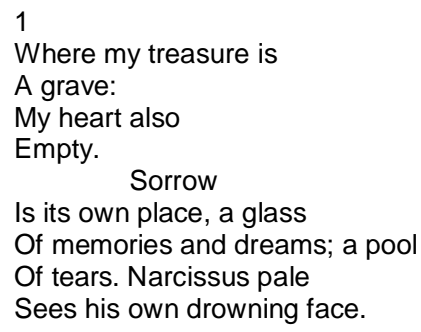

\section{1}

Donde mi tesoro es

Una fosa:

Mi corazón también

Vacío.

\section{La tristeza}

- Morada de sí misma - espejo es

De sueños y recuerdos, estanque

De lágrimas. Pálido Narciso,

Ahogándose, contempla su propia faz. (Raine [1973] 1981: 30-31)

La traducción de Martínez Nadal de este primer poema recupera las alusiones bíblicas y, por cierto, también las clásicas y míticas, pero deja entrever, no obstante, lo que será, según se mostrará, una constante en el resto del poemario: un desplazamiento que afecta, en el plano micro, el nivel morfosintáctico; y en el plano macro, la variedad del registro. La modulación, para usar las palabras de Vinay y Darbelnet ([1958] 2006), es un procedimiento que modifica el plano semántico, pues al introducir variación en el orden sintáctico, las categorías de las palabras, las nociones de tiempo y espacio, las negaciones, la voz, las relaciones de causa y efecto, el traductor está alterando también, y sin lugar a dudas, el punto de vista o perspectiva; en definitiva, el sentido último del poema se ve afectado a partir de esta transformación. En el ejemplo citado esto ocurre principalmente en la segunda parte del poema en la que el traductor introduce las siguientes modificaciones. En el original, la tristeza (sorrow) podría estar ligada sintácticamente a corazón (heart) de la primera parte del poema; sin embargo, el adjetivo posesivo (its) que sigue a sorrow del complemento predicativo (Sorrow/ is its own place) también da lugar a interpretar la cláusula como independiente de la anterior. En su versión original, el poema habilita la lectura de los dos sentidos de manera simultánea. Por su parte, en el poema traducido, el traductor opta por la segunda opción. Así, la indefinición referencial del adjetivo posesivo 
aparece definida en la traducción que anula la posibilidad de cualquier otra referencia para comenzar una nueva idea a partir de la noción de tristeza en la segunda parte del poema. Este cambio impacta sobre el sentido ya que el poema original no deja en claro con qué entidad debemos relacionar ese adjetivo posesivo. En otras palabras, ¿la tristeza se configura como el lugar/morada del corazón? O, como propone y define el traductor, ¿la tristeza es morada de sí misma? En efecto, el predicativo que le corresponde a tristeza en el original, sorrow is its own place, queda parcialmente anulado en el poema traducido por el uso de la cláusula parentética. El verbo ser ha pasado a dominar la escena de la siguiente definición que replantea, sin causa aparente, el orden de la enumeración del original: la tristeza es espejo de sueños y recuerdos. Por último, la modificación del objeto de contemplación de Narciso introduce otro cambio significativo. En el poema original, Narciso contempla que su propio rostro se ahoga, mientras que en el texto traducido Narciso contempla su rostro mientras se ahoga. La mirada innovadora del mito se desvanece en la traducción de Martínez Nadal, aun si con la anuencia de la propia poeta, como el traductor declara en sus notas ${ }^{8}$. Por otro lado, el poema traducido sí logra recrear, precisamente a partir de esta decisión, parte de la musicalidad que registran el segundo y el último verso del poema: grave = face; fosa = faz. En cuanto al registro, aquí se esbozan algunas prácticas que se vuelven cotidianas en la traducción. La decisión de usar "morada" cuando el original solo proponía "place" contribuye a emplazar el discurso poético en un ámbito más específico que el que presenta el original. Así, la traducción teje una continuidad con el epígrafe que no aparece explicitada en el texto original.

Con respecto a la reelaboración del lenguaje poético, la cual atañe tanto al plano sintáctico, como al estilo y al registro, es de interés revisar, entre otros, los poemas 2,5 y 6 :

2

From the hollow sphere of space

Echo

Of a lonely voice

That cries, my love, my love;

I do not know

Whether I spoke or heard
2

De la hueca esfera del espacio

Eco

De soledosa voz

Que grita: amor mío, mi amor.

Y yo no sé

Si yo dije o escuché

\footnotetext{
${ }^{8} \mathrm{Al}$ respecto, podrá consultarse la nota al poema 1, correspondiente al verso 8.
} 
The word

That fills all silence.
La palabra

Que colma todo silencio.

(Raine [1973] 1981: 30-31)

Como se puede apreciar, en el poema 2 el traductor ha elegido el adjetivo "soledosa" para verter en español el sentido de "lonely", que acompaña al nombre "voice". Esta elección ha sido, por supuesto, deliberada. En sus notas, Martínez Nadal indica que esa es la única ocasión en la que emplea un adjetivo que puede resultar "arcaizante" para recrear el sentido de un término de uso corriente en el original inglés (“lonely"). E significado de "soledoso", tal como argumenta el traductor, aparece como justo para establecer el tono de melancolía y pesar que caracteriza el original. Si bien no hay dudas de que esto es acertado, el desplazamiento en el registro tiene consecuencias en dos planos diferentes. Por un lado, en el ámbito del poema traducido, la imagen de melancolía y pesar se elabora a partir de un término que reviste un mayor carácter poético que el empleado en el texto original $y$, por el otro, la elección de un término poco corriente contribuye a conformar la imagen de un lector culto que no solo domina el español corriente, sino que también conoce otros registros de uso de la lengua.

Asimismo, el poema ilustra una estrategia común a toda la traducción: el empleo de términos más específicos para designar nombres o cualidades que, en inglés, tienen un carácter más general. Por ejemplo, el verbo "hear" aparece traducido como "escuchar" y el verbo "fill" como "colmar". La elección de "colmar" parece responder, nuevamente, a la necesidad de inscribir el poema en la escena de un lenguaje más poético y metafórico. Sin embargo, el caso del verbo "hear" es diferente. Como se ha señalado, este poema resulta una continuación del poema 1, en el que se instala el tema de Narciso y Eco. En este sentido, la alusión a un verbo de percepción auditiva general, como "hear", no resulta intrascendente, puesto que en la evocación del mito, según la Metamorfosis de Ovidio, la ninfa Eco es relegada a ser una voz que solo puede decir/ repetir lo que oye, que no tiene presencia física y que solo puede ser oída, pero no escuchada, razón por la que queda excluida de la posibilidad de una relación de reciprocidad. El poema de Raine recupera este aspecto del mito para vincular el sentir del yo lírico, no correspondido en su amor, con la soledad de Eco. En el interior del poema, esta relación se gesta a través de la mención de la ninfa y del empleo de los verbos "speak" y "hear". En este caso, se desvanece en parte la alusión clásica y mítica y se gesta una nueva voz en el poema traducido. Asimismo, el cambio de orden sintáctico que afecta la traducción de la forma de vocativo "my love, my love", la cual, en la versión de Martínez 
Nadal, es vertida a través de los sintagmas "mi amor, amor mío" introduce otra modificación de sentido significativa. Tratándose de una alusión al decir de la ninfa Eco, quien solo puede repetir el final de las frases que oye, este cambio de orden parece no hallar justificación, más que en la voluntad del traductor de elaborar un lenguaje que, en español, es más complejo y poético.

En cuanto al empleo de términos más específicos, también es de interés cotejar el poema 6, que a continuación transcribimos:

6

Memory: beyond recall

The linnet's song,

The clover-scented air;

Yet we were there,

My love and I together in one house.

Home is the sum of all

The days that sheltered us:

The place of no return.
6

Memoria: Más allá del recuerdo

El canto del jilguero,

El aire del meliloto perfumado;

Sin embargo allí estuvimos nosotros,

Mi amor y yo juntos en una casa.

Hogar es la suma de todos

Los días que nos albergaron;

El lugar del no retorno.

(Raine [1973] 1981: 34-35)

En este poema, Martínez Nadal traduce el sintagma "the cloverscented air" del tercer verso, por "el aire del meliloto perfumado" (op. cit.: 34-35). Sin dudas, el original, aun si no lo explicita, debe aludir a la variedad de la especie conocida en inglés como "sweet clover" o "melilot", que es la planta que puede perfumar el aire. Los lectores del original que compartan la visión del paisaje que Raine describe podrán reconocer el aroma que rodea el poema. La traducción hace explícita la cuestión y opta por el nombre "meliloto", que resulta mucho más específico en español, para resolver la recreación del sintagma nominal. En otro plano de análisis, se aprecia que la preposición "de" podría capturar mejor el sentido de la expresión que la contracción "del", que impone un orden morfosintáctico diferente. Asimismo, en el segundo verso, la elección del término "jilguero" para traducir el sentido de "linnet" crea una imagen sonora diferente en el poema traducido. El canto del jilguero aparece, seguramente, como un canto más reconocible y, a la vez, más poético, que el del pardillo para el lector de la traducción.

Por su parte, la traducción del poema 5 contribuye, incluso en mayor grado, a la creación de un lenguaje más poético, en este caso a través de dos recursos: el empleo del hipérbaton y la selección de términos que, en la actualidad, registran un uso poético de manera prácticamente exclusiva. 
5

I cannot weep

Who, when I turn to you in thought

Behold a mystery so deep,

A world upheld upon a breath

That comes in life and goes in death

Troubling dark leaves upon

a starry bough.

Who dreams our lives I do not know,

Nor in what land it is we meet.
5

No puedo llorar yo

Que cuando a ti en pensamiento vuelvo

Contemplo misterio tan profundo,

Un mundo suspendido de un soplo

Que viene en la vida y va en la muerte

Turbando hojas oscuras en

estelífera rama.

No sé quién nuestras vidas sueña,

Ni cuál la tierra de nuestro encuentro.

(Raine [1973] 1981: 34-35)

El hipérbaton, ausente, en términos generales, en el texto original, aparece como un recurso privilegiado que recorre toda la traducción. Este recurso colabora con la creación de un ritmo y musicalidad particulares en el poemario traducido, los cuales le confieren una sonoridad propia. Se trata de una figura que hace más complejo el estilo de la traducción y que la acerca, por otra parte, a la obra de poetas como Bécquer o el propio Góngora que han hecho un uso singular de este procedimiento. De ello da cuenta, por ejemplo, el orden sintáctico correspondiente a los versos primero, segundo y séptimo de este poema. Por otra parte, se evidencia que la decisión de verter el sintagma "starry bough" por "rama estilífera" en el verso sexto colabora con la afiliación del poema a un ámbito más poético ${ }^{9}$. En el mismo sentido, se construye, como en el caso anterior, la imagen de un lector, que está familiarizado con el empleo del hipérbaton como recurso propio de la poesía y con el uso poético del lenguaje en el espacio del poema. Se trata de exigencias interpretativas que no están presentes en el original sino que son establecidas a partir de los parámetros que plantea la traducción para sus nuevos lectores.

Finalmente, en el juego de apropiaciones que implica toda traducción prevalece, como indicamos en la Introducción, una lectura determinada del texto original, un modo de interpretarlo y hacerlo propio a través de la lengua meta en relación con el ámbito de la cultura receptora y de la literatura local. En este sentido, el poema 22 cobra especial relevancia:

22

Mist-dwellers:

Love in part remembers,
22

Huéspedes de la niebla: Amor en parte recuerda

\footnotetext{
${ }^{9}$ Asimismo, el poema 11 ilustra también el cambio de registro y estilo ya aludido. En este poema, el verso "Waking to an ignorant day" es traducido como "Al despertar en ignaro día" (Raine [1973] 1981: 40-41). El énfasis es mío.
} 


But who we are,
And where before our eyes had
met -
In soul's far wanderings
What is that glory we forget? ${ }^{10}$

\author{
Quién somos \\ Y dónde antes nuestros ojos \\ se encontraron - \\ En el lejano vagar de las almas \\ ¿Qué gloria es esa que olvidamos? \\ (Raine [1973] 1981: 50-51)
}

Como se podrá advertir, la traducción de este poema es clave para establecer un lazo estrecho y explícito entre el poemario y la poeta y la tradición poética española. Tal como apunta Martínez Nadal en su prólogo y en la nota al poema 22, la decisión de traducir el sintagma "mist-dwellers" por "huéspedes de la niebla", en lugar de "moradores de la niebla" o "habitantes de la niebla", obedece a su voluntad de vincular la poesía de Raine con la de Gustavo Adolfo Bécquer (1836-1870), en particular con la rima LXXV, en la cual Bécquer ([1871] 2001) hace uso de esa expresión: "¿Será verdad que, huésped de las nieblas,/ de la brisa nocturna al tenue soplo,/ alado sube a la región vacía/ a encontrarse con otros?" (op.cit.: 29$30)$. Por otra parte y como se aprecia prontamente, en nuestra lengua, el sintagma elegido reviste un carácter más poético que otras de las opciones que el traductor pudo haber considerado: "moradores/habitantes de la neblina". De todos modos y aun cuando, como aduce el traductor, la lectura del poemario puede traer al lector al espacio de las famosas Rimas, en tanto ambas obras transitan algunas preocupaciones comunes como el problema de la poesía, del amor y de la muerte a través de un lenguaje despojado de artificios, el traductor es consciente, pues así lo señala en el prólogo, de que Raine no conocía la obra del poeta sevillano. Se trata de una de las transformaciones que impone el traductor a fin de construir un vínculo entre dos poetas que volverá, sin dudas, más aceptable la obra traducida para el tipo de lector que instituye la traducción, a saber, un lector que pueda reconocer y apreciar los ecos de la poesía española en la obra de Raine.

\section{CONCLUSIONES}

A lo largo de este artículo, hemos examinado algunos aspectos que conciernen a la traducción poética en relación con la traducción al español de On a Deserted Shore de la poeta inglesa Kathleen Raine realizada por el escritor y crítico español Rafael Martínez Nadal. En términos generales, el análisis de la edición bilingüe nos permite aseverar que la traducción crea

\footnotetext{
${ }^{10}$ En la transcripción que se presenta, he subsanado dos errores tipográficos.
} 
una imagen no solo de la poeta y de su obra, sino también del traductor, que adquiere visibilidad a través de la adopción de distintas decisiones y estrategias, que le confieren una voz propia y autónoma. Es necesario apuntar que el poemario traducido logra capturar y recrear en español aquello que se percibe como el "espíritu del original" y su calidad poética. La poesía de Raine cobra una nueva vida en la versión del traductor español, la cual, destinada a circular en nuevos espacios lingüístico-culturales, se presenta como diferente. Según se ha mostrado en el estudio de casos, la traducción de Martínez Nadal opera según pautas definidas y anticipadas en el prólogo de la obra y sostenida en el texto traducido y en las notas finales de la edición.

Ahora bien, el análisis pormenorizado de este caso de traducción, que ha atendido tanto al espacio de la textualidad como al de la paratextualidad, nos faculta a esbozar algunas reflexiones y observaciones particulares. En primer lugar, el examen de los elementos paratextuales de la obra estudiada, así como la consideración de artículos críticos y periodísticos muestra que la tarea del traductor ha sido legitimada por distintos agentes, que son relevantes para la introducción de un texto literario en una cultura determinada. En este sentido y según hemos indicado, se advierte la visibilidad y autonomía del traductor en el espacio paratextual de la obra y su posibilidad de construir una voz propia y autorizada. En efecto, el prólogo, que registra la relación de camaradería y colaboración que existió entre Raine y Martínez Nadal, contribuye a configurar una imagen del traductor que aparece como conocedor de la autora, su obra y de la tradición en la esta se inscribe. Asimismo, el hecho de que Hiperión haya sido responsable de la publicación indica la confianza que el mercado editorial depositó en la calidad de la obra y también en la labor del traductor. Es posible afirmar que, fiel a su propósito, Martínez Nadal ha interpretado la obra en pos de captar las ideas generadoras de los poemas y escuchar el eco de las alusiones bíblicas, clásicas y míticas que lo caracterizan, para luego recrear el poemario a partir de los elementos y redes de sentido que le ofrecía el español y en relación con sus propias hipótesis acerca de la lectura y recepción efectivas de su traducción en el ámbito de la cultura receptora.

En segundo lugar, el estudio de la obra muestra que en la traducción opera un cambio significativo que atañe al estilo de Raine. Ciertamente, el traductor modifica el estilo lacónico de la poeta mediante el uso de palabras que no se ajustan, en principio, a la simpleza y frescura que distinguen el original. En este mismo sentido, es posible afirmar que el texto traducido da cuenta del empleo de un registro de lengua más alto así como de la 
especificación, en distintos poemas, de términos que aparecen como más generales en el texto fuente. En distintos pasajes del poemario traducido, se evidencia la construcción de un lenguaje y estilo más poéticos.

Finalmente, el examen del plano morfosintáctico evidencia que la traducción busca adecuarse a los patrones que rigen las normas y pautas lingüístico-culturales y literarias correspondientes al espaciio en el que circulará la traducción. Se trata de una traducción que observa, en gran medida, el principio de aceptabilidad (Toury, [1978] 2006), aun si esta decisión compromete, en ocasiones, la recreación del sentido. Más aún, la construcción de lazos de intertextualidad explícitos con la poesía de Bécquer introduce una modificación en la obra traducida, la cual, probablemente, hará más fluida su circulación en el escenario local, en el que podrá leerse, incluso, como parte o, al menos, como muy cercana a la literatura nacional. Este modo de apropiarse del original da lugar a la creación de una nueva voz poética, la cual, aun si bella, se distancia de la imagen y de la enunciación poética que celebra el original. Estos procedimientos colaboran con la construcción de un lector de la traducción que puede caracterizarse como culto y versado en poesía española. Esta imagen de lector, se condice, como indica Doce (2013), con el perfil de la editorial Hiperión en la década de los años ochenta. El caso estudiado reafirma, pues, la idea de que la traducción poética conjuga, necesariamente, la creación artística, la reflexión detenida sobre la práctica y la consiguiente toma de posición frente a la tarea de la traducción.

REFERENCIAS BIBLIOGRÁFICAS

Alonso, Dámaso (ed.), Antología de poetas ingleses modernos. Madrid: Gredos, 1963.

BASSNETT, Susan, "Transplanting the Seed: Poetry and Translation". En: S. Bassnett y A. Lefevere, Constructing Cultures. Essays on Literary Translation. Cleveland, Philadelphia, Toronto, Sydney, Johannesburgo: Multilingual Matters, 1998, pp. 57-75.

BÉCQUer, Gustavo Adolfo, Rimas y leyendas. Santiago de Chile: Pehuén Editores, [1871] 2001.

BIBLIA, El Nuevo Testamento. Evangelio según San Mateo, 6.21. Disponible en: http://www.vatican.va/archive/ESL0506/ PUG.HTM [Consultado el 20/08/2013]

CALdeRón de la BARCA, Pedro, Life's a Dream. London: Hamish Hamilton. Traducción de Kathleen Raine y Rafael Martínez Nadal, 1968. 
"En una desierta orilla", La Nación, 26 de julio de 2013. Disponible en: http://www.lanacion.com.ar/1604410-en-una-desierta-orilla\#comentar [Consultado el 20/08/2013].

JAKOBSON, Roman, "En torno a los aspectos lingüísticos de la traducción." En: Ensayos de lingüística general. Barcelona: Editorial Seix Barral S. A., [1959] 1981, pp. 67-77.

"Kathleen Raine pide la vuelta a la filosofía de Platón", El País, 11 de marzo de 1981. Disponible en: http://elpais.com/diario/1981/03/11/cultura/353113207_850215.html [Consultado el 21/08/2013].

Keebley, Brian, Kathleen Raine. Poetic Imagination and the Vision of Reality. London: Temenos Academy, 2008.

King James Bible "Authorized Version", Cambridge Edition. Disponible en http://www.kingjamesbibleonline.org/Matthew-Chapter-6/ [Consultado el 20/08/2013].

JONES, Francis R., "Literary Translation". En: M. Baker y G. Saldanha (eds.) Routledge Encyclopedia of Translation Studies. London y New York: Routledge, $2^{\circ}$ edición, [1998] 2009, pp. 152-157.

LEFEVERE, André, "La traducción: el lenguaje". En: Traducción, reescritura y la manipulación del canon literario. Salamanca: Ediciones Colegio de España, [1992] 1997, pp. 125-137. Traducción de María Carmen África Vidal y Román Álvarez.

MARTíneZ NADAL, Rafael, "Prólogo". K. Raine, ([1973] 1981) En una desierta orilla. Edición bilingüe. Prólogo, traducción y notas de Rafael Martínez Nadal. Madrid: Ediciones Hiperión, 1981, pp. 9-25.

MASSEAU, Paola, Aproximación teórica a la crítica de la traducción poética. "Le Cimetière marin" de Paul Valéry. Tesis Doctoral, Universidad de Alicante, 2007. Disponible en:

http://www.lluisvives.com/servlet/SirveObras/67926282109025010410 457/030796.pdf [Consultado el 22/10/2013].

MounIN, Georges, Les problèmes théoriques de la traduction. Paris: Éditions Gallimard, 1963.

OVIDIO, Metamorphoses/ Metamorfosis (Libro III). Barcelona: Editorial Brugera, S. A., [c. 1-8] 1983. Traducción y notas de Antonio Ruiz de Elvira.

Plotino, Select Work of Plotinus. Bohn's Philosophical Library (205-270). Traducción de Thomas Taylor, $2^{\circ}$ edición, [c.270], 1895.

RaINE, Kathleen, On a Deserted Shore. Dublin; London: The Dolmen Press/ Hamish Hamilton, 1973. 
__- En una desierta orilla. Edición bilingüe. Prólogo, traducción y notas de Rafael Martínez Nadal. Madrid: Ediciones Hiperión, [1973] 1981.

The Lion's Mouth. London: Hamish Hamilton, 1977.

- "What is the Use of Poetry?". En: Temenos Academy Review. Kathleen Raine Memorial Issue. Londres: Temenos Academy, [c.1990] 2004, pp. 11-26.

RoBINSON, Douglas, Who translates? Translators Subjectivities Beyond Reason. Albany: State University of New York Press, 2001.

TouRY, Gideon, "The Nature and Role of Norms in Translation". En: L. Venuti (ed.) The Translation Studies Reader. New York y London, Routledge, $2^{\circ}$ edición, [1978] 2006, pp. 205-219.

VENUTI, Lawrence, Translation Changes Everything. Theory and Practice. Londres y Nueva York: Routledge, 2013.

VINAY Jean-Paul y DARBELNET, Jean, "A Methodology for Translation". En: L. Venuti (ed.) The Translation Studies Reader. New York y London: Routledge, $2^{\circ}$ edición, [1958] 2006, pp. 128-137. Traducción de Juan. C. Sager y M.-J. Hamel.

WILLSON, Patricia, La Constelación del Sur. Traductores y traducciones en la literatura argentina del siglo XX. Buenos Aires: Siglo XXI, 2004. 